\title{
MANNERS MAKETH MAN: \\ A COMPARISON OF THE ETHICS OF ANENCEPHALIC AND BABOON ORGAN DONATION
}

\author{
Aaron Manners
}

\begin{abstract}
A scarcity of organs available for transplantation dictates a need new sources. Two possible solutions to this problem are the use of organs from anencephalic newborns and those from baboons. This is a comparison of the ethics of these two sources, asking whether the sentient primate or the non-sentient human is the more appropriate donor. It is sustained that the definition of personhood requires the upper brain to be capable of functioning, resulting in an ability for selfconsciousness. There is an important difference, it is argued, between the human body and the person within it. As such, the anencephalic infant should not have the same rights as the sentient person. It follows that the life of the baboon, which is capable of feeling pain and has some cognitive ability, is more deserving of protection than that of the anencephalic neonate. In reaching this conclusion, a broad Utilitarian analysis is applied, treating the suffering of an animal of some worth, but the 'suffering' of the anencephalic newborn as irrelevant. It is acknowledged that on a Kantian analysis, the baboon is not a rational creature, but reference is made to Kant's belief that animals should nonetheless be treated with respect. It is found that Kant's theory would not prohibit a well-regulated system of xenotransplantation, but that the weight which Bentham attaches to an animal's suffering does provide insuperable difficulties. This is further explored, with the conclusion that the causing of any suffering makes a xenotransplantation program unjustifiable.
\end{abstract}

\section{A. INTRODUCTION}

Anencephaly is a condition which affects approximately one in every thousand births, ${ }^{1}$ resulting in a baby without a developed brain, with no cognitive capacity. It is by no means an unheard-of affliction. Upon finding out that a foetus is anencephalic, doctors consistently recommend a termination of the pregnancy. Of those which are born at term, approximately $28 \%$ are not born living. ${ }^{2}$ The prognosis for the remaining babies is invariably death, with all but six out of a study of two hundred

\footnotetext{
${ }^{1}$ T. W. Sadler, 'Embryology of Neural Tube Development' [2005] Am J Med Genet Part C 2, 6.

2 Jaquier M, Klein A, Boltshauser E., 2006. 'Spontaneous pregnancy outcome after prenatal diagnosis of anencephaly', [2006] BJOG 951, 951.
} 
and eleven dying within six days, and $67 \%$ dying within the day. ${ }^{3}$ By the point of natural death, certain organs are unsuitable for transplantation. For the organs of the anencephalic newborn to be of any practical benefit, they must be harvested from the foetus before it would have naturally died. ${ }^{4}$ This is incompatible with the normal understanding of allotransplantation in that it is required that the donor consents in some form and is indeed dead. With xenotransplantation, though, the issues of death and consent are legally overcome, as the law does not afford animals the same degree of protection which it affords humans. The question that will be addressed is whether it is ethically justifiable to use the organ of a living, sentient and healthy baboon, to save the life of a person, where there is the option of using the organ of an anencephalic baby, who without permanent life support would die without the capacity for any emotion or suffering. The answer to this question will rest on whether the only relevant factor is sentience, or whether there is something more significant in determining the relative statuses of a human and another living creature. Throughout this exploration it will be argued that the anencephalic infant is the more ethically suitable donor, since the only appropriate factor is whether the donor will suffer or not, however palatable this may seem.

It is agreed by all commentators that there is a scarcity of organs available for transplantation. As the number of people on waiting lists for operations continues to grow, more people are dying who could be saved were an organ to become available. ${ }^{5}$ By 2003 , almost a decade after the launch of the NHS Organ Donation Register, it held the details of more than ten million people who had consented to parts of their post mortem bodies being used for allotransplantation. For the United Kingdom's organ shortage to be sated, though, this number needed to be doubled, to represent roughly one third of the population. ${ }^{6}$ Furthermore, to compound this problem, the donor system in the United Kingdom is not routinely

\footnotetext{
${ }^{3}$ ibid 951.

${ }^{4}$ Alison Davis, 'The Status of Anencephalic Babies: Should Their Bodies be Used as Donor Banks?' [1988] JME 150, 151.

${ }^{5}$ Sheila McLean and Laura Williamson, Xenotransplantation, (Ashgate Publishing Ltd 2005), 1.

${ }^{6}$ Royal College of Surgeons of England, 'The Report of the Working Party to Review Organ Transplantation', (Royal College of Surgeons, 1999) in McLean (ibid) 2, para. 135.
} 
consulted upon death by hospitals, so in the absence of any well-informed friends or relatives, it is entirely possible that usable organs remain unused, especially given the limited time frame within which doctors are obliged to work. ${ }^{7}$ Indeed, these are problems which have been noted by Parliament. Legislation such as the Human Tissue Act 2004 created the ability for family members and even longstanding friends to give permission for organs to be used in the absence of any evidence of the deceased's consent. Furthermore, the British Medical Association has advocated moving to a system of 'presumed consent", which would require one to actively opt out of donation, again in conjunction with the relevance of the views of close relatives in absence of such a decision. This is an issue by no means unique to the United Kingdom and moreover has been noted, with particular attention to the case of anencephalic donors, by the Supreme Court of Florida where Rogan J found 'an unquestioned need for transplantable infant organs' ${ }^{\prime 9}$. Clearly, any good source of organs for transplantation would be welcome.

The case of the anencephalic infant will first be explored, and following this the focus will turn to xenotransplantation and with that a comparison with the ethics of anencephalic allotransplantation. Initially, the issues that the anencephalic presents shall be crystalised. Put simply, the question that needs to be answered is firstly to what degree the anencephalic infant is dead, and with that fit for being a donor, and secondly whether it is sufficient ethically to define the baby as dead, where its heart might still be beating, or whether there is more to humanity than whether or not the brain is functioning, taking into account the Kantian view of human life.

\section{B. The AnenCePhalic NeWborn}

According to the evidence that was put to the Supreme Court of Florida, up to and including 1990, twelve successful allotransplantations had taken place using anencephalic donors, but these had been 'most successful when the anencephalic immediately was placed on life support and its organs used as soon as possible without regard to the existence of

\footnotetext{
${ }^{7}$ British Medical Association (BMA), Organ Donation in the 21st Century, (BMA, 2000) 2.

${ }^{8} \mathrm{BMA}(\mathrm{n} 7) 13$.

${ }^{9}$ Re T.A.C.P. [1992] Supreme Court of Florida, November 12 1992, No. 79, 582, 16.
} 
brain-stem activity'. ${ }^{10}$ Indeed, although the kidneys and other organs can be successfully taken for transplantation after death, the heart needs to be taken while it still beats. Furthermore, the body has the ability to react to stimulus, even if it is unable to suffer. ${ }^{11}$ That is to say that there are developed areas of the brain that are responsible for reflex reactions, although there is no brain to interpret this as pain. The baby is not dead within the definition of the English Common Law, since the anencephalic newborn can have a partially functioning brainstem. ${ }^{12}$ This too is true of the definition which has been reached by the Harvard Committee in America. ${ }^{13}$ Additionally, following a cardiopulmonary definition of death, the baby is alive when it can sustain its own heartbeat and breathing by way of the brain stem, which it is sometimes able to do for a matter of hours or even days.

In English Law, the removal of an anencephalic's beating heart is therefore prima facie a case of homicide. This too was the judgment reached by the Supreme Court of Florida when they considered the question in 1992. ${ }^{14}$ Indeed, this is what Alison Davis has argued in saying 'I may not be a doctor, but even I know it is not in anyone's best interests to have their heart removed while they are still alive. ${ }^{15}$ It is the use of emotive language such as this which makes this question such a difficult one to answer. But, it is equally difficult to think that somebody may be suffering, in need of a heart, that could be supplied by an infant who is otherwise destined to make no use of it and would be unaware were it removed.

In Re T.A.C.P, the Court found that the law defined death as a cardiopulmonary failure, but allowed death also to be found where the functions of the lungs and heart were being artificially maintained and 'irreversible cessation of all functions of the entire brain, including the brain stem ${ }^{16}$ had occurred. The condition of an anencephalic infant who was able to sustain a heartbeat and breathing, despite the lack of presence

\footnotetext{
${ }^{10}$ ibid 7.

${ }^{11}$ Davis (n 4) 151.

${ }^{12} R v$ Malcherek; $R v$ Steel [1981] 2 All ER 422 (EWCA).

${ }^{13}$ Francis L. Delmonico, 'Interview with Dr Joseph Murray', [2002] AJT 803, 805.

${ }^{14}$ Re T.A.C.P. (n 9) 18.

${ }^{15}$ Davis (n 4) 152.

${ }^{16}$ National Conference of Commissioners on Uniform State Laws 1980, 'Uniform Determination of Death Act, Section 1'.
} 
of the forebrain, was said to be incompatible with both of these statements of death. ${ }^{17}$ What the Court failed to appreciate, though, was that there is a significant difference between cortical brain function and activity in the brain stem. The functioning of the brain stem in facilitating cardiopulmonary activity is nothing more than a reflex action, and as such represents the existence of nothing that makes a person different to any other animal. The law quite rightfully affords different protection to human life from that which is given to the life of animals. For example, only causing "unnecessary suffering" ${ }^{18}$ of an animal is prohibited in English Law, as opposed to the infinitely more serious crime of murder against a person. It seems almost superfluous to point out that the vast majority of people are content with the killing of animals for meat but would find the concept of cannibalism abhorrent. And so, it seems to be a non sequitur that an anencephalic newborn, who has the capacity for none of the characteristics that make humans unique, is treated as any other properly developed person. Indeed, Dr Levine, a professor of medical ethics, has said that 'our brain stems do not differ substantially from the brain stem of a fish" ${ }^{19}$ and as such an anencephalic infant 'has more in common with a fish than a person ${ }^{20}$. The person does not exist in a mere physical presence; if this were the case then a cadaver would be afforded the same legal protection as a living and healthy person. Instead, the person exists in the capacity for mental activity, which the anencephalic never has. Irreversible cortical brain death, especially in the anencephalic baby, should be seen as total death for the purposes of organ transplantation, since it represents the death of the person, even if the body is still active in limited and passive ways.

This leads on to a necessity of defining exactly what is meant by human life. It has so far been argued that the anencephalic infant is not 'alive' in the sense that it is a living person, despite the fact that its body is capable of responding to stimulus and can, albeit for a limited time, sustain a heartbeat and breathing. It will now be explained why it is sufficient that the anencephalic newborn is lacking all cognitive ability in

\footnotetext{
${ }^{17} \operatorname{Re}$ T.A.C.P. (n 9) 18.

${ }_{18}^{18}$ Animal Welfare Act 2006, s 4.

${ }^{19}$ Sara Chartrand, 'Legal Definition of Death is Questioned in Florida Infant Case', The New York Times (New York, 29 March 1992).

${ }^{20}$ ibid.
} 
deciding whether or not it is dead. The most prominent work that has been done to date on this subject is that of Green and Wikler. It is their argument that there is a difference between the signs of life 'of human bodies rather than those of persons'. ${ }^{21}$ This is very similar to the argument that has been advanced so far, that it is incongruous to protect an anencephalic newborn in law in the same way that any other person is protected, when they share none of the human's sentient characteristics. Green and Wikler write that were the brain of A hypothetically to be transplanted into the body of $\mathrm{B}$, A would continue to live, whereas $\mathrm{B}$ would not. It follows from this, they say, that where A's brain is destroyed before transplantation, A no longer continues to live, which leads to the conclusion that 'a brain-dead body has similarly been stripped of the identity of the formerly associated person'.$^{22}$ It is the death of this 'person', rather than the ceasing to function of the body with which Green and Wikler are concerned. By this argument, it is shown that the 'person' of an anencephalic newborn is never in existence. There is no person. As such, the anencephalic infant, as a donor, is at this stage on an ethical par with that animal donor, since neither qualifies for status as a 'person'. In neither case is a person being killed so that organs can be harvested.

But perhaps there is more to 'personhood' than a strict question of whether or not the upper brain is capable of sustaining cognitive capacity. Stephen Holland cites the argument of 'personhood"23, in determining the ethical comparison of the anencephalic and animal donors. This argument is that there is more to a person than mere sentience. Indeed, the science of xenotransplantation has been developed because human life is prized more highly than that of animals. It seems a logical conclusion, therefore, that as the child of a human, the anencephalic is a less ethically sound donor than any animal could be. But although the anencephalic infant may share many physical human characteristics, it is unable to fulfill the integral criteria that make a person distinct. A human, said Locke, is defined in terms of self-consciousness. ${ }^{24}$ By this definition, the body without an upper brain cannot be a person.

\footnotetext{
${ }^{21}$ Green and Wikler, 'Brain Death and Personal Identity", [1980] PPA 105, 128.

22 ibid 126.

${ }^{23}$ Stephen Holland, Bioethics, (Polity Press 2003) 32.

${ }^{24}$ Linda Zagzebski, 'The Uniqueness of Persons', [2001] J Relig Ethics 401, 412.
} 
Furthermore, Kant believes that 'rational beings are called persons ${ }^{25}$, and that it is this rationality which gives rise to moral obligations. Indeed, with regards to non-rational creatures, Kant writes that 'we can dispose of [them] as we please ${ }^{26}$. This is a category which he has created to deal with animals other than humans, but the anencephalic newborn fits into it too, however uncomfortable a fact this may be. Kant's conception of morality in the second formulation of the categorical imperative is that to be capable of being 'an end in itself ${ }^{27}$, a creature must be capable of 'rationality'. There is no debate that this is a group into which the anencephalic infant cannot be shoehorned. To this end, the baby is capable of being treated 'as a means to an end' ${ }^{28}$. Both the arguments of Locke and Kant show that there is indeed more deserving of protection than mere sentience, but that 'personhood' is still founded in something which nonetheless requires the cortical functioning. It is incorrect to treat a brain dead anencephalic infant, albeit with functioning brain stem, in the same way as any other living person. There is a material difference between the meanings of 'personhood' and 'human'. 'Personhood' can only come about through the functioning of the upper brain.

Although perhaps philosophically sound, ethically many find that this view is indefensible. One critic describes the concept that only the rational are worthy of protection as an 'extreme anthropocentric', opinion that is rarely adopted. Indeed, it is difficult to sustain an argument that only the rational creature has any worth, and to state that worth is denoted solely in terms of morality. This is not necessarily at odds, though, with the idea that the rational being is superior and should be treated as a special case. There is a difference between establishing that the anencephalic infant lacks 'personhood' and deciding that they are worthy of no ethical concerns at all.

\footnotetext{
${ }^{25}$ Immanuel Kant, The Groundwork of the Metaphysics of Morals 1785 (Mary J. Gre gor tr., CUP, 1998) 4:428 79.

${ }^{26}$ Immanuel Kant, Anthropology, 1798, (Mary J. Gregor tr. Nijhoff, 1974) 127, 9.

${ }^{27}$ Kant (n 25) 4:436, 85.

28 ibid $6: 381,513$.

29 A. S. Daar, 'Ethics of Xenotransplantation: Animal Issues, Consent, and Likely Transformation of Transplant Ethics' [1997] WORLD J SURG 975, 976.
} 
Kant's belief that rationality leads to a discrete form of worth, and thus that rational beings should treat other rational beings as a 'means to an end ${ }^{30}$ is useful for creating a hierarchy of importance, but it is best understood merely as demonstrating that a person has 'absolute and unconditional value, ${ }^{31}$. It need not be used to demonstrate that any creature lacking rationality has no value. By following Kant's argument, one is not restricted to concluding that any non-rational creature is equally unworthy of respect. Indeed, Wood writes that Kant does not believe that animals can be treated solely as tools, but instead are worthy of 'gratitude and affection", ${ }^{32}$. It is clear, therefore, that Kant's second formulation of the categorial imperative is not contradictory to a conclusion that the anencephalic newborn is a more ethically appropriate donor than the sentient animal. Instead, this is surely in-keeping with Kant's philosophy. For example, Kant is strongly against 'agonizing physical experiments [on animals] for the sake of mere speculation, or whose end can be achieved in other ways ${ }^{33}$. This indubitably shows that suffering should not be needlessly inflicted upon non-rational living creatures. The non-sentient infant, lacking in 'personhood', is therefore better than the animal for choosing as a donor. It has now been shown that the anencephalic newborn should be correctly regarded as dead, despite any heartbeat, for the purposes of organ donation. Furthermore, falling outside of the category of the 'rational person', it is clear that the infant need not be treated with the same degree of protection that is appropriate for persons, but can instead be ethically used to benefit other humans. Finally, the anencephalic baby has been shown to be worthy of less protection than animals, due to its inability to suffer.

\section{Extending This Principle}

The anencephalic newborn has been shown to lack 'personhood' and be suitable for organ donation. It will now be asked whether the infant can ethically be indefinitely kept on artificial life support, allowing it to grow

\footnotetext{
${ }^{30}$ Kant (n 25) 6:381, 513.

31 Allen Wood and Onora O'Neill, 'Kant on Duties Regarding Nonrational Nature', [1998] Proceeding of the Aristotelian Society, Supplementary Volumes 189,189.

32 ibid 191.

${ }^{33}$ Kant (n 25) 6:443, 564.
} 
so as to cultivate organs suitable for allotransplantation ${ }^{34}$ into larger and older patients. The discussion begins with the problem of consent. It is lawful for medical treatment to be given to a patient who is unable to consent where it is in their best interests. For this reason, ventilation and life support for an anencephalic newborn could be justified within law because in line with current medical practice they are not dead, within the cardiopulmonary and whole-brain definitions. ${ }^{35}$ It can then be argued that to artificially keep somebody alive solely for the purpose of preserving the state of their organs so that they can be donated at a later time is in fact a tort and could even give rise to criminal liability. ${ }^{36}$ Even with the case of an unconscious child under 16, where the parents can give consent, this is limited to cases where it is in the patient's best interests. ${ }^{37}$ These are the usual objections to life support solely to aid a later transplantation, but where the patient is not a person, the issue of consent surely cannot be of relevance. Returning to the words of Alison Davis, 'it is not in anyone's best interests to have their heart removed ${ }^{38}$ either, but without the upper brain and with that cortical function, the anencephalic infant is not an 'anyone'. Kant's reasoning too, with regards to respect for animals, cannot be in point here because it centers on an obligation to not cause unnecessary suffering. With the brainless infant there can be no such suffering. Indeed, it may not be normal practice to artificially prolong the life of an anencephalic newborn for organ donation purposes, but parents who decide to give birth to an anencephalic foetus often do so for the purpose of allowing their organs to be used. This was the reasoning of the parents of Theresa Ann Campo Pearson, with whom the Re T.A.C.P. case was concerned, who discovered the condition in

\footnotetext{
34 'Allotransplantation' is a hybrid of Classical Greek and Latin, derived from the Classical Greek ' $\alpha \lambda \lambda \mathrm{oc}^{\prime}$ ', meaning 'other' and the Latin 'trans' and 'plantare' meaning 'across' and 'to plant' respectively. It is used to refer to the moving of an organ between two bodies of the same species which are genetically different, contrasted with xenotransplantation and autotransplantation, where the donor is the same as the recipient. Because of this definition, there is no conflict between the use of the term with regards to the anencephalic infant and the fact that the infant does not satisfy the criteria to be a 'person'; the term 'allotransplantation' refers to the genetics of the body and not the status of the individual.

${ }^{35} \operatorname{Re} F[1990] 2$ AC 1 (UKHL).

${ }^{36}$ Robert Francis, 'An Ethical Debate: A legal comment', [1995] BMJ 718, 719.

${ }^{37}$ Kennedy and Grubb (eds), Medical Law, (3rd edn, Butterworths 2000), 824.

${ }^{38}$ Davis (n 4) 152.
} 
prenatal tests but decided to 'donate their daughter's organs for transplant ${ }^{39}$. Some parents feel so strongly about this desire that they are willing to explore different hospitals to find one which is willing to transplant the organs, where they have been 'poo poo'd' ${ }^{40}$ by others. In this case, as with the case of artificial life support, the life is being prolonged not for any benefit to the foetus or neonate, but as a means to an end. The only material difference, though, is that one is an artificial action where the other is an omission. In terms of utilitarianism, a body of philosophy which to this point has been neglected, both concepts are similar.

Utilitarianism is concerned with creating the greatest utility, or happiness, for the greatest number of people. Applying this principle strictly, one should not only answer any problem with the solution that provides the greatest net utility, but is morally obliged to perform any action which would cause an increase. That is to say that if it were to be realised that the termination of an anencephalic foetus would increase utility, that would be an obligation. Omissions should be treated no differently to actions. Without any cortical functions, an anencephalic neonate does not feature in a utilitarian equation. But, in finding this balance, utilitarianism demands that all effects are taken into account. This would of course include not only any potential patients who could be helped, but also any relatives who may be positively or detrimentally affected by the use of the infant's body. It seems inappropriate to be concerned with third parties when assessing techniques which have the capacity to save and end lives, but in a utilitarian philosophy an emotional harm caused can be measured against the benefit of life-saving treatment, however negligibly.

One anencephalic newborn has the potential to save two lives, by way of the heart and the liver, whilst also greatly benefitting a number of others by way of kidneys and corneas, and other transplantable tissues. ${ }^{41}$ Davis recognises that the infant is not to be taken into account for the purposes of utility, but goes on to suggest that this concept 'would justify

\footnotetext{
${ }^{39}$ Chartrand (n 19).

40 ibid.

${ }^{41}$ James Walters and Stephen Ashwal, 'Organ Prolongation in Anencephalic Infants: Ethical \& Medical Issues, in The Hastings Center Report (1988) Vol. 18, 19.
} 
using any of us as a donor if someone of the status of Einstein ${ }^{42}$ needed a transplant. Indeed, Einstein may be able to create more utility by using a heart than many other people, but where Davis' argument seems to falter is that she fails to take into account those who might be affected by the abuse of a person who may otherwise live. Furthermore, it would surely be greatly unsettling to live in a society where one knew that their organs might at any time forcibly be used to save another person. Although this is a most inexact science, it is easy to conclude that this ubiquitous unease would outweigh any benefits of this 'Robin Hood' style reallocation system.

A similar mistake is made by Ethics and Social Impact Committee of the Transplant Policy Centre in their statement that 'no conflict of rights ${ }^{43}$ occurs in a utilitarian analysis of anencephalic donation. A Kantian conception of the status of the person may be unable to take into account the effect on third parties such as relatives, but this is something to which utilitarianism is sensitive, looking at society as a whole. Returning to the original issue, although there may be little difference in principle between failing to terminate a pregnancy, and artificially sustaining the infant after birth, potentially for a number of years, there is surely a difference in the effect which this has on others. Relatives, particularly parents, may feel glad that the newborn is delivered, and that it is given a fair chance, and may further feel glad that it has saved the lives of other babies, but in most cases it seems fair to assume that this pleasure would be overtaken by prolonged upset and a lack of 'closure' if the baby were to kept alive until adult sized, diminishing the net utility. Moreover, remaining in the factual, rather than philosophical, arena, the number of anencephalics which survive birth and are viable is very low. There is no need to cultivate these babies for any significant time to allow older patients to be helped, since there are sufficient younger hosts for transplantation, with more than 400 young hearts being required each year in American alone. ${ }^{44}$ When factors such as public discomfort at babies being artificially grown being taken into consideration, and the

\footnotetext{
${ }^{42}$ Davis (n 4) 150.

43 The Ethics and Social Impact Committee, 'Anencephalic Infants as Sources of Transplantable Organs', in The Hastings Center Report, (1988) Vol. 18, $28,29$.

44 Peter McCullagh, Brain Dead, Brain Absent, Brain Donors, (Wiley and Sons, Chichester, 1993), 143.
} 
fact that the lives of younger patients may have to be sacrificed in order to save older patients, the utilitarian justification fails. It therefore cannot be justified philosophically to artificially maintain an anencephalic infant's life for a significant time, merely to cultivate larger organs. There is justification, though, to keep the neonate on life support for sufficient time to successfully perform a transplantation, partly to avoid any feelings of futility on the part of third parties, but primarily to save lives. It would be a question of fine utilitarian judgment as to whether this could be done against the will of a parent.

This concludes the initial discussion of the ethics of the anencephalic organ donation. It has been shown thus far that an anencephalic neonate should be treated as never having been alive for medical and legal purposes, although the laws of England and of America adopt definitions which conflict with this. The neonate may be 'human' but is not a 'person', and as such should be subject to none of the protection afforded to people in law. Adopting a Kantian view of personhood, the infant is outside of the class of rational beings along with all other animals, but it is not true that each member of this class is therefore necessarily the same. The same Kantian thought allows for a hierarchy, which is defined primarily in terms of an ability to suffer. In this hierarchy, the anencephalic infant necessarily comes lower down than sentient creatures such as the baboon, for this reason seemingly providing a more ethically sound organ source. This argument though, on a utilitarian basis, does not extend to allowing the artificial sustaining of anencephalic life until such time as the organs can be used for transplantation into physically mature hosts.

\section{THE BABOON}

Just like the anencephalic infant, the baboon is incapable of rational thought, but does not lack every characteristic which separates the homo sapiens from more base forms of natural life. The problems with xenotransplantation are as much practical as they are ethical and philosophical. Although the chimpanzee may prove to be a scientifically viable source of organs, it is considered an endangered species, and so it is difficult to justify further depleting their numbers. ${ }^{45}$ This could perhaps

${ }^{45}$ Daar (n 29) 976. 
be overcome in time by specific rearing of these animals in captivity. The baboon, on the other hand, although more common, breeds slowly and it would therefore take great amounts of time and money to produce a usable number in captivity. ${ }^{46}$ Other problems include the inherent technical difficulties in cross-species medicine, and the potential for unexpected and uncorrectable xenozoonosis, ${ }^{47}$ similar to the current struggle against HIV in much of the world, which is thought to have originated in monkeys. ${ }^{48}$ In short, xenotransplantation is an immature area of science.

The ethical issues are greatly similar to some of the concerns regarding the anencephalic case. The issue of sentience is again significant. This has partly been dealt with by way of the Kantian argument of non-rationality. One argument which did not arise with regards to the anencephalic was the degree of suffering which can legitimately be caused. This will be discussed with regards to Benthamite philosophy. It will be examined whether there are material differences between different species of animal. A final question that will be posed is whether, given that the anencephalic infant is a more ethical donor than the baboon, whether the baby could be used to perform a xenotransplantation upon the baboon, were science to permit this.

Xenotransplantation is an attractive option, partly because it neatly sidesteps any of the murky issues such as consent which necessarily legally surround the use of human organs. Furthermore, it would avoid the issues presented when an organ is available, but a patient is not, or perhaps when an organ is needed but a suitable human cadaver cannot be found in time. ${ }^{49}$ We are currently comfortable throughout the world in breeding animals for the purpose of food production, and indeed pigs are widely used to provide certain tissues such as heart valves. Furthermore, we have the understanding and indeed the technology to keep suffering to a minimum. ${ }^{50}$ In this respect, xenotransplantation is a practical option.

\footnotetext{
46 ibid.

${ }^{47}$ Cross-species disease.

${ }^{48}$ Daar (n 29) 977.

${ }^{49}$ Holland (n 23) 30.

${ }^{50}$ James Giordano and Bert Gordijn (eds), Scientific and Philosophical Perspectives in Neuroethics (CUP, 2010) 193.
} 
It is unnecessary and inappropriate to discuss other practical issues in great depth, such as the possibility of the xenozoonosis and the large price of producing suitable donor animals. Indeed, it should be noted that scientific ability is less developed with regards to xenotransplantation than it is with regards to the donation of organs from anencephalic infants, although not even this has yet been perfected. This, as well as other practical concerns, are significant to the extent that any ethical argument in favour of using the baboon is lessened by the recognition that in real terms it is potentially less suitable.

One possible connotation of xenozoonosis, though, is its ramifications in terms of consent. Until this point, little consideration has been given to the patients who receive all of these hypothetical organs. It has been tacitly assumed that they would be glad to receive any organ which they could, since the other option would be sickness and death. But, an issue which is exclusive to the case of the baboon is that the transplantee must act differently after the operation and possibly for the rest of their lives. While the science is young, Daar believes that a xenotransplant will lead the recipient to agree to lose all privacy and confidentiality in the course of consenting to the operation, so as to facilitate frequent monitoring. ${ }^{51}$ With the risks of new diseases similar to HIV being unknown, the host will have to be quarantined from leading a normal life for a significant period. Such restrictions could not be optional, and once the operation was complete, it would need to be impossible to opt out, for both personal health concerns and the protection of the public at large. Daar is correct to conclude that we would "need to forego "consent" for a legally binding "contract" a truly pertinent observation, but it should be developed to add that this is only the case because of the stage of medical knowledge, given the rarity with which such operations have been conducted in the past. If and when xenotransplantation becomes better understood and safer, this argument will become irrelevant, following the creation of data bases from early successful recipients ${ }^{53}$. Indeed, it may be a concern for now, but as it is

\footnotetext{
${ }^{51}$ Daar (n 29) 977.

52 ibid.

53 Marian Michaels, 'Infectious Concerns of Cross-Species Transplantation: Xenozoonoses', [1997] WORLD J SURG 968, 972.
} 
only a temporary problem, as with the development of any new medicine, it should not be given too much weight.

It is the belief of Kant that suffering of animals should be limited and that they should be treated with respect, even if they are not rational. Immediately, this creates concerns with xenotransplantation in that it is a pre-requisite that the donor animals are raised in special closed conditions so as to ensure they are 'specified-pathogen free" ${ }^{54}$. If allowed to live in conditions as similar to their natural habitat as possible, Kant's concerns can be overcome, where suffering is not needlessly inflicted. But the concerns of Bentham are more extensive and perhaps more problematic. Jeremy Bentham is frequently quoted as writing 'The question is not Can they reason? no Can they talk: but Can they suffer?" ${ }^{55}$ In this maxim, Bentham directly contests the work of Kant. The concern is raised that if reason is the sole criterion, then a mature horse is 'a more rational, as well as a more conversable animal ${ }^{56}$ than any new born human. This criticism can be overcome, though, by taking an ever so slightly nuanced Kantian view, that is cognitive potential not ability. Upon this meaning, which would even be strengthened by the importance that potential plays in Bentham's own utilitarian philosophy, the anencephalic newborn would remain outside the Kantian category, as would animals. But there is something to be said, still, for Bentham's views. Although an animal may be outside the Kantian category of personhood, Kant and Bentham agree that their suffering is regrettable. Kant believes that it must be justified.

Indeed, the baboon does have the capacity to suffer. It is one of the animals most closely related to the human. It is paradoxical almost that because they are so closely related to us, and perhaps therefore deserving of many rights which accrue to humans, argues Daar, they are thought to be one of the most suitable matches for xenotransplantation. ${ }^{57}$ A question to address, though, is whether it is sufficient to say that the baboon suffers, or whether it must be stated to what extent the baboon can suffer.

\footnotetext{
${ }^{54}$ Daar (n 29) 976.

55 B. E. March, 'Ethical Problems: Animal Welfare, Animal Rights', [1984] BIOSCIENCE 615, 617.

${ }^{56}$ Jeremy Bentham, Introduction to the Principles of Morals and Legislation, 1789 (J.H. Burns and H. L. A. Hart eds. Clarendon Press 1996) footnote 283.

${ }^{57}$ Daar (n 29) 976.
} 
Singer is of the opinion that such a discussion is of little consequence, since the "principle of equal consideration" ${ }^{, 58}$ requires that all like interests between species are equally treated. He writes that "pains of the same intensity and duration are equally bad, whether felt by humans or animals ${ }^{59}$. But surely cognitive capacity should in some way effect the weight which is given to the potential suffering of pain. It seems inappropriate to compare the complex emotions that might be suffered by a person in accompaniment to a painful stimulus, such as fear of repeat incidents, upset at the reasons behind the cause of the pain and even the possibility of blaming oneself for getting into such difficulty, to the more base interpretation of suffering as merely suffering which an animal might experience. Both the human and the animal may feel pain in the same way, but the accompanying feelings will surely be greatly more distressing for the human. But, although this difference can be found between the person and the non-human, studies have shown that 'the linguistic capacities of even the higher primates must not be exaggerated ${ }^{\prime 60}$. That is to say that even though animals such as baboons are capable of learning certain tasks and exhibiting human like behaviour, in reality their cognitive ability is not as great as it may seem. In this respect, a division can be found between different animals, particularly between humans and non-humans, but other differences must not be overstated. The variance of suffering between the pig and the baboon may not in fact be that great.

Furthermore, it has been argued that it is justifiable for humans to attach more weight to human suffering than to that of animals 'because human beings have certain relations to other human beings which they do not have to animals. ${ }^{61}$ That is to say that by dint of such factors as economic and familial relationships, and communication between one another, Francis and Norman argue that it is understandable that humans treat each other with more respect than they treat animals, and value their

\footnotetext{
${ }^{58}$ Adam Kolber, 'Standing Upright: The Moral and Legal Standing of Humans and Other Apes', [2001] STAN J L 163, 187.

${ }^{59}$ Peter Singer, 'Animal Liberation: A New Ethics for Our Treatment of Animals', New York: New York Review (1975) 19.

${ }^{60}$ Leslie Pickering Francis and Richard Norman, 'Some Animals are More Equal than Others', [1978] PHILOSOPHY 507, 513.

${ }^{61}$ ibid. 508.
} 
interests more highly. This argument is again almost Kantian, in that is prizes the fruits of rationality and cognitive ability above more rudimentary and instinctive relationships, but it says nothing about physical suffering. It therefore seems that Singer's argument of equal consideration may have its merits when comparing between different animals, but that it should not apply to humans whose rationality and cognitive function clearly and justifiably sets them apart with regards to suffering. To create a hierarchy of different sentient animals, though, is perhaps irrelevant.

To this extent, it is not ethically perfect to bring animals up in captivity so as to create a stock of organs, but it seems to be no better to rear a pig than a baboon. In either case, there is a need for specialised facilities with animals being birthed by caesarian section and 'under current standard practices, the sow is not recovered from the procedure and the piglets are hand-raised under sterile conditions ${ }^{62}$, remaining forever separated from other animals. There is nothing natural about this. Furthermore, genetic engineering, which has already been endorsed by a United Kingdom Government advisory committee, has the potential to increase animal susceptibility to illness and inflict far greater suffering. ${ }^{63}$ We may be happy to raise animals specifically to produce meat, and kill them for this purpose, but there are material differences between that process and this. It does not follow that one can be used to justify the other. The only way, it seems, that the rearing of animals for xenotransplantation can be justified is in terms of necessity and a balancing of rights, in a pseudo-utilitarian way. If a person needs an organ, then an amount of suffering is going to be caused to them if they do not receive it. Their suffering will be greater than that which can possibly be caused to an animal. In this way, the process can be legitimised.

This is logically sound, but somewhat ethically unsatisfactory. Although Kant felt that animals could be used as a means by people, it did not follow that this power should be abused. If the realities of a large scale xenotransplantation programme are as distressing as they seem,

\footnotetext{
62 Mark Hanson, Lilly-Marlene Russow and Charles McCarthy, 'Case Study: A xenotransplantation protocol', in The Hastings Center Report, (1999) Vol. 29, 22-25, 24.

${ }^{63}$ Daar (n 29) 980.
} 
perhaps the exact balance of suffering is irrelevant. Xenotransplantation may have crossed Bentham's 'insuperable line ${ }^{, 64}$, and in this respect it may well be inappropriate to justify xenotransplantation by any utilitarian argument. It is key, therefore, that the anencephalic infant is incapable of any form of suffering, and it is primarily this factor which makes the neonate the ethically better donor than any sentient animal.

\section{E. SOMe Conclusions}

It has been concluded that the anencephalic newborn is a better donor than the baboon, and it has further been concluded that an animal's suffering requires justification and cannot be needlessly inflicted. It is a stage of the conclusion that the neonate is not a person and has no ability to suffer, even as a non-human. It seems a logical conclusion therefore that the organs of the neonate could be used, were science to make this possible, for xenotransplantation into the baboon. Indeed, an animal's suffering is recognised, albeit not as greatly as that of a person, and any a strict utilitarian argument might not only therefore authorise such a procedure, but could even require it. It was left undecided whether the organs of the neonate could be used for transplantation against the consent of the parents, as this was considered to be too fine a hypothetical balancing act to have any meaning. Let us assume for a moment that the parents are happy for the organs to be used to save an animal. Consent has no legal meaning here, since we are dealing with a non-person, but it is relevant for the sake of the wider utilitarian arguments. This argument permits the use of organs for this purpose, since it would increase the utility of relatives. If the animal's utility is of any worth, this greater increases net utility, but in a strict utilitarian sense the animal would not be treated as part of society. But, repeating the argument against artificially prolonging the life of the neonate to cultivate larger organs, this was considered to be unnecessary since there is no shortage of smaller organs required. This seems to be one of the greatest guards against using these organs to save animals. Indeed, it would quite clearly be preferable, even, to grow these larger organs for the purpose of saving older people, since every argument advanced thus far has shown how the person is to be prized above any animal. Furthermore, such operations

${ }^{64}$ Bentham, (n 56) footnote 283. 
could be seen as interfering with the fine balance of nature and her natural selection if conducted with wild animals. This argument would not apply in the case of domestic animals.

In conclusion, the non-sentient baby should not be given the same rights as any person. There is a vital differentiation to be found between the human body and the person within it. It is possible for the former to function after the death of the latter. With the case of the anencephalic infant, birth does not take place. There is no person to protect. It is not physical appearance that defines the person but instead the ability to reason, or at least a potential to do so. In the case of the brain dead infant, this capacity can never exist. The baboon, on the other hand, although non-rational in the Kantian sense, has some cognitive ability. Most importantly, even if not self-conscious, it can suffer. Where the baby can physically react to pain, the baboon can respond to it. It is definitely not justifiable to inflict such suffering where there is the option of saving a human life without causing any suffering at all. Moreover, any xenotransplantation programme would cause such a degree of suffering that it cannot be justified at all, even where there exists no viable alternative. An animal may not be capable of manners, but it is by no means devoid of emotion. 